\title{
Bladder Mixed Adenocarcinoma
}

National Cancer Institute

\section{Source}

National Cancer Institute. Bladder Mixed Adenocarcinoma. NCI Thesaurus. Code C39839.

A variant of bladder adenocarcinoma that histologically consists of more than one growth pattern such as enteric, mucinous or signet ring types. 